\title{
Monthly solar radiation in the tropical Atlantic Ocean: Can its spatial variations be captured by the current configuration of the PIRATA moorings?
}

\author{
Mélodie Trolliet and Lucien Wald \\ MINES ParisTech, PSL Research University, O.I.E. - Center for Observation, Impacts, \\ Energy, Sophia Antipolis, France \\ Correspondence: Mélodie Trolliet (melodie.trolliet@mines-paristech.fr)
}

Received: 19 January 2018 - Revised: 26 June 2018 - Accepted: 27 June 2018 - Published: 11 July 2018

\begin{abstract}
The present work aims at contributing to the proper design of networks of measuring moorings with regard to the downwelling solar irradiance at surface (DSIS). Considering the yearly profiles of the monthly DSIS, this article studies whether the 17 moorings within the existing PIRATA network are well geographically distributed so that they capture the spatial variations of the yearly profiles in the tropical Atlantic Ocean. A clustering technique is performed onto the HelioClim-3v5 satellite-derived gridded dataset of DSIS spanning 12 years, thus yielding 17 zones of similar yearly profiles. It was found that the mean yearly profiles of several zones are similar to the measured ones at the three moorings having enough measurements to perform the comparison. Zones have clear connections with the climatology of the region and circulation regimes. The geographical distribution of the moorings has been analysed with regard to the zoning. In the northern region of the tropical basin, each zone contains at least one PIRATA mooring. Hence, the configuration of the PIRATA network is appropriate to reflect the spatial variations of the yearly profiles in this northern part. In the southern basin, the coverage is less complete; several zones do not contain any PIRATA mooring. Thus, the network does not capture the spatial variations of the yearly profiles and this may induce misinterpretation of the PIRATA measurements at synoptic scales. It was also found that the computation of latitudinal or longitudinal averages of irradiance may be wrong if based solely on measurements from moorings without taking into account the spatial representativeness of a mooring.
\end{abstract}

\section{Introduction}

Getting high quality measurements at fixed measuring stations is very challenging, especially when the maintenance of the measuring instruments is difficult, such as at sea. The oceanic stations are in most cases moorings checked at each passage of scientific vessels. The maintenance of these isolated stations represents a huge investment to guarantee high quality measurements. When designing a measuring network, attention should be brought to the number and locations of the moorings among many other aspects (Augustine et al., 2000; Stokes and Schwartz, 1994; Wolfe and Gutman, 2000). The number of stations is a trade-off between the need to put out a large enough array for a long enough period of time to gain new insights into the studied phenom- ena and several constraints including limited funding, costs of maintenance, number of instruments, personnel..., which is especially crucial at sea (Servain et al., 1998). Too many stations may result in an over-investment with a negligible scientific gain; too few stations may lead to a misrepresentation of the spatial variability of the variables of interest, with possible biases in analyses and interpretation of the measurements. Techniques have been proposed for the optimal design of networks of measuring stations at ground (Bogárdi et al., 1985; Bras and Rodríguez-Iturbe, 1976; Stauffer et al., 2000; Vinnikov et al., 1999). They are often based on the analysis of a priori knowledge of the spatial correlation and more generally of the geostatistical properties of the variables of interest and the space and timescales to study. Such knowledge is hardly known over the ocean due to lack of measurements. 
Hence, there is no agreed protocol for the optimal design of a network at large scale over the ocean.

The present work aims at contributing to the proper design of networks of measuring moorings. No solution is proposed; the focus is on the study of the existing PIRATA network and the assessment of its capability to depict the spatial variations of the solar radiation at synoptic scales.

The PIRATA (Prediction and Research Moored Array in the Tropical Atlantic) network is made up of 17 moorings. It was established to improve knowledge and understanding of ocean-atmosphere variability in the tropical Atlantic Ocean (Bourlès et al., 2008). Each mooring measures several variables, including the downwelling solar irradiance at surface and hereafter abbreviated as DSIS. The DSIS is the downwelling solar radiation passing through and scattered by the atmosphere and received at the ocean surface. At a given location, the DSIS is varying noticeably during a year due to changes in the solar radiation received at the top of the atmosphere and in the cloud presence and their varying optical properties. The yearly cycle, i.e. the seasonal variability, is by far the most energetic cycle compared to the other timescales, irrespective of the geographical location or of the local climate (Bengulescu et al., 2016, 2017, 2018). As a consequence, this study focuses on the monthly DSIS.

Considering the yearly profiles of the monthly DSIS, this article addresses the following question: can the spatial variations of the monthly DSIS be captured by the current configuration of the PIRATA moorings? The current configuration is determined by the location of the 17 moorings. The question may be reformulated as: are the 17 moorings geographically distributed in such a way that they capture the various yearly profiles? To answer this question, 17 zones, or classes, are created by a clustering technique applied to a satellite-derived gridded dataset of DSIS spanning 12 years. Geographical points in a given zone exhibit similar variations of the monthly DSIS. Then, it will be checked that there is one or more PIRATA mooring in each zone. If yes, and assuming that each PIRATA mooring exhibits yearly cycles of the DSIS similar to those of the zone to which it belongs, it will be concluded that the configuration of the PIRATA network is appropriate to reflect the spatial variations of the monthly DSIS.

The PIRATA and satellite-derived gridded datasets are presented in Sect. 2 as well as the clustering method. In Sect. 3, the resulting zoning is partly validated by comparing the yearly profiles of the monthly DSIS of the PIRATA moorings to those of the corresponding zones for the moorings with enough data. A further validation is made in this Section where the classes are analysed in light of known physical processes at synoptic scales. The Sect. 4 discusses the ability of the configuration of the PIRATA network to reflect the spatial variability of the monthly DSIS. A brief discussion on the method and its possible applications are given in Sect. 5. Section 6 concludes the paper.

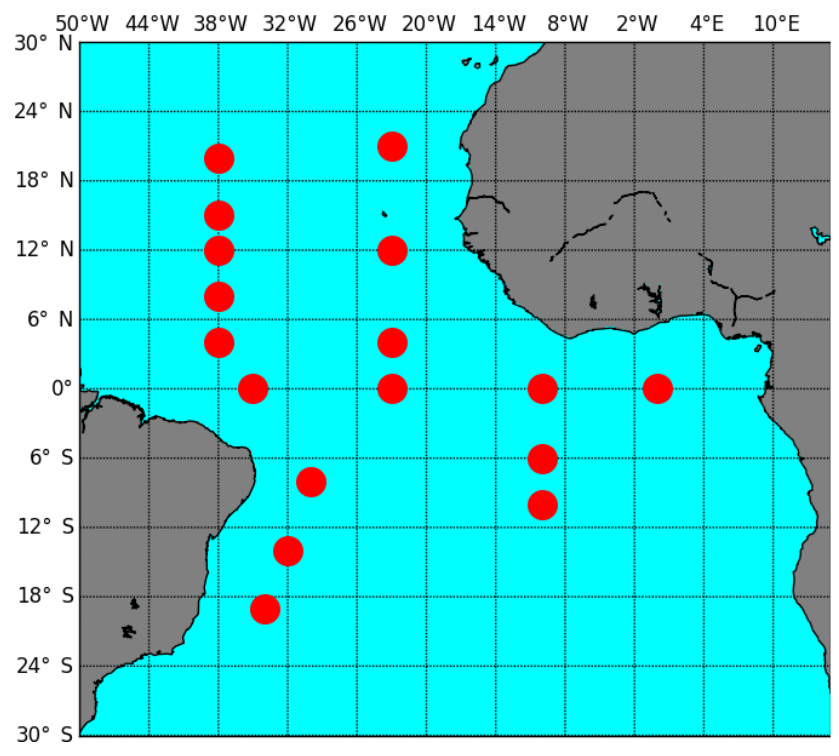

Figure 1. Map showing the location of the PIRATA buoys.

\section{Data and methods}

\subsection{The PIRATA network}

The PIRATA network results from a joint project between Brazil, France and the United States of America (Bourlès et al., 2008; see the Web site https://www.pmel.noaa.gov/ gtmba/ for more information, last access: 1 July 2018). The implementation of PIRATA started in 1997 with an array of backbone moored buoys in the Atlantic Ocean. Extensions were added starting from late 2005. The present study was performed using seventeen meteo-oceanic buoys in the Atlantic Ocean, between the latitudes $19^{\circ} \mathrm{S}$ and $21^{\circ} \mathrm{N}$ (Fig. 1). The buoys are of ATLAS type and are gradually replaced by T-FLEX systems from 2015. Among other sensors, the buoy is equipped with an Eppley pyranometer that measures the DSIS as 2 min averages. The sensors are deployed for about one year on average before replacement during every yearly servicing cruise.

The measurements can be downloaded as $2 \mathrm{~min}$ averages from the web site of the Global Tropical Moored Buoy Array (GTMBA) of the Pacific Marine Environmental Laboratory (PMEL) of the National Oceanic and Atmospheric Administration (NOAA) in the USA. Measurements undergo quality checking at NOAA and suspicious measurements are flagged. The number of measurements and their quality depend on the mooring and year. Many moorings exhibit missing data or suspicious measurements in the early years of the network and the situation tends to improve. The analysis of the data and their flags indicates that all moorings seem to work properly. As a consequence, it is assumed that each mooring exhibits the same overall quality as the others and has its place within the network. 
A subset of moorings has been selected in order to validate the results of the clustering technique and their measurements will be considered as reference for the comparison of yearly profiles. These moorings offer high quality data spanning at least two years with a limited number of missing data. A first selection was made by using the quality flags of the NOAA. As the data must serve as reference and considering the different sources of uncertainty which the PIRATA measurements are subject to (incorrect sensor levelling, shading caused by close structures, accumulation of dust, dew, water-droplets, bird droppings, miscalibration of sensors, electronic failures, time shifts in data loggers, maintenance mishandling, buoy motions, etc. see e.g. Muneer and Fairooz, 2002; Foltz et al., 2014), an additional quality control was performed at MINES ParisTech. The quality control comprises several tests of the 2 min DSIS against extremely rare limits and physically possible limits (Korany et al., 2016). Values falling outside the limits were excluded from the time-series. Eventually, a visual analysis was performed to remove suspicious values. Only measurements that passed all tests successfully were kept. The hourly mean of DSIS was computed by averaging the 30 measurements within this hour if all measurements were declared valid. Otherwise, the hourly mean was declared invalid. Following the guidelines of the World Radiation Data Center (http://wrdc.mgo.rssi.ru/, last access: 1 July 2018), daily means were then computed if all hourly values were valid, and the monthly means were computed if more than 25 days were valid within the month. The yearly mean is then computed as the mean of the 12 valid monthly means as recommended by the World Meteorological Organization (http://www.wmo.int/pages/prog/wcp/ccl/guide/ documents/Normals-Guide-to-Climate-190116_en.pdf, last access: 12 June 2018). Eventually, the subset comprises three moorings:

- mooring at 0 and $10^{\circ} \mathrm{W}$ for the period 2011-2012

- mooring at $6^{\circ} \mathrm{S}$ and $10^{\circ} \mathrm{W}$ for the period 2011-2012

- mooring at $19^{\circ} \mathrm{S}$ and $34^{\circ} \mathrm{W}$ for the period 2011 to 2013

\subsection{The HelioClim-3 v5 dataset (HC3v5) remapped}

Meteorological re-analyses and images acquired by satellites observing the ocean surface provide means of getting a synoptic view of the DSIS. Boilley and Wald (2015) and Trolliet et al. (2018) compared the DSIS output of ERAInterim, ERA5, MERRA, and MERRA-2 re-analyses to PIRATA measurements. They observed that the re-analyses often report cloud-free conditions while actual conditions are cloudy, yielding an underestimation of surface irradiance by these data sets, and reciprocally, cloudless conditions as cloudy, yielding an overestimation. The standard deviation of the errors was large as a whole and the biases varied considerably in time and space. Such changes in bias denote a spatial distortion of the DSIS field and will induce errors in the description of the variability. The authors do not recommend the use of such re-analysis datasets but instead suggest exploiting satellite-derived datasets of DSIS. Three of these, the HelioClim-3 version 5 (HC3v5), Surface Radiation Dataset - Heliosat (SARAH-2) and Copernicus Atmosphere Monitoring Service (CAMS) Radiation Service v2 datasets, have been compared to the PIRATA measurements in Trolliet et al. (2018). The authors concluded that the quality of the three satellite-derived datasets is fairly similar. They also concluded that each of these is appropriate for studying the variability of the downward solar irradiance at the surface of the tropical Atlantic Ocean.

For the sake of the simplicity, the HC3v5 database has been selected for this study. Images of the Meteosat Second Generation satellites are routinely processed by MINES ParisTech and a companion company Transvalor to yield the HC3v5 dataset. HC3v5 covers Europe, Africa, the Middle East, parts of South America and the Atlantic Ocean. It is available from 2004 up to the present with a 15 min time step. The spatial resolution depends on the pixel position and is approximately $3-4 \mathrm{~km}$ in the tropical Atlantic Ocean. The processing method is the Heliosat-2 method (Rigollier et al., 2004; Lefèvre et al., 2007), modified by Qu et al. (2014). The method itself, as well as the HC3v5 dataset, have been the subject of several comparisons against measurements of DSIS made at land-based sites, see e.g. Bengulescu et al. (2017), Eissa et al. (2015), Marchand et al. (2017, 2018), or Thomas et al. (2016a, b).

The DSIS from HC3-v5 has been downloaded from the SoDa Service (http://www.soda-pro.com/, last access: 1 July 2018) (Gschwind et al., 2006). This web service performs the integration over time and the DSIS was downloaded as time-series of daily means from 2005 to 2016 . The data have been geographically projected onto a regular grid in latitude and longitude with a spacing of $0.25^{\circ}$. The monthly means of the DSIS were constructed for each calendar month and each cell over the 12 years using the rules of the World Radiation Data Center discussed above. The standard deviation of daily means within each calendar month was also computed.

\subsection{The clearness index $K T$}

The clearness index, usually noted $K T$, is defined as the ratio of the daily or monthly means of the DSIS to the corresponding irradiance at the top of the atmosphere. Both quantities are given by the SoDa Service. The dependency of KT on the solar zenithal angle, and hence on seasonal changes in the solar position, is much less pronounced than that of the DSIS. $K T$ is an indicator of the optical transparency of the atmosphere. It depends on several factors such as cloud presence and properties, content in water vapour or aerosol properties. As clouds are the most influent factor on the extinction of the solar radiation by the atmosphere, $K T$ is a means to characterize their gross influence. $K T$ is typically close to 0.8 in 

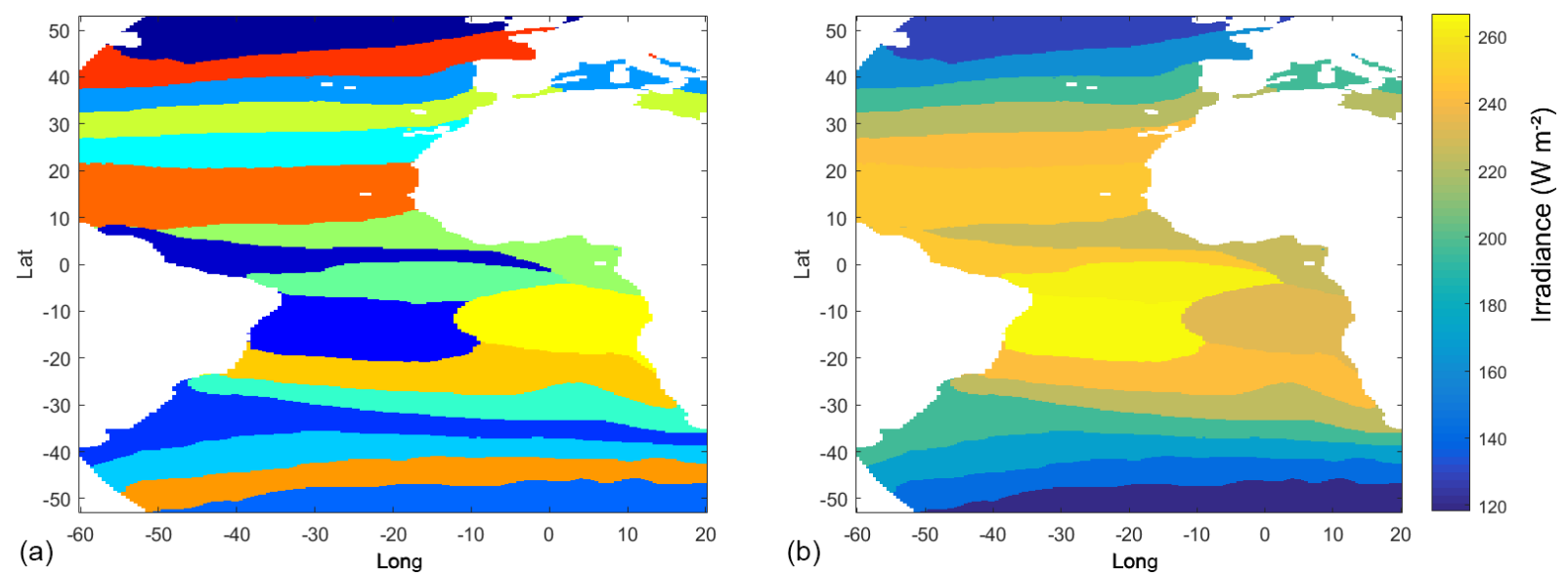

Figure 2. Map of the 17 resulting classes of DSIS (a). Map of the same classes but whose colour indicates the yearly mean of the DSIS (b).

cloud-free conditions and close to 0.1 in overcast conditions. Similarly to the DSIS, the monthly means and standard deviations of daily $K T$ were constructed for each calendar month and each cell.

\subsection{Zoning by a $k$-means classifier}

The spatial and temporal variations of the DSIS on the one hand and of $K T$ on the other hand, have been summarized using spatial zoning. A cluster analysis was applied to input state vectors made of the 12 monthly means and 12 monthly standard deviations of the HC3v5 dataset to create clusters or classes. Two cells belong to the same class if they exhibit the same yearly profile of both the monthly means and the standard deviations. The clustering aims at forming classes such that cells of a given class are as similar as possible, while they are as different as possible from cells of other classes. A hierarchical cluster tree was created by applying the algorithm of Ward (1963), where the similarity between two cells is given by the Euclidean distance computed on the two corresponding state vectors. The closest cells are first aggregated and produce a new object (or class) whose state vector is an average of the individual state vectors. The distances between this class and all other cells are re-computed. The process is iterated to construct a hierarchical cluster tree, until there is a unique cluster. The Ward algorithm permits computation of the intra-class variance as a function of the number of classes. It reaches its minimum when no clustering is made, i.e. when the number of classes is equal to the number of cells, and is a maximum when there is only one class. It increases slowly as the clustering proceeds, and the number of classes decreases. If a sharp increase of the intra-class variance occurs at a given number of classes, it indicates the forming of a heterogeneous class from two homogeneous classes and may signal the end of the process of clustering. In this case, and similarly to the findings of Diabaté et al. (2004) who performed a similar clustering for the whole Africa, no sharp increase is found. As the objective of this article is to study the geographical distribution of the 17 PIRATA moorings, a limit of 17 classes was set.

The zoning has been applied to all cells in the Atlantic Ocean between $53^{\circ} \mathrm{S}$ and $53^{\circ} \mathrm{N}$. The areas north and south of the tropical region have been added on purpose in order to help the verification of the methodology. Each class exhibits a yearly profile of monthly means corresponding to the means of the yearly profiles of all cells belonging to the class. This yearly profile is hereafter called a typical profile. Finally, the different classes were plotted on a map of the Atlantic Ocean.

\section{Zoning of the irradiance}

\subsection{Map of the classes of irradiance}

Figure 2a shows the map of the 17 classes of irradiance with colours chosen randomly in order to maximize the contrast between two adjacent classes. One observes that the classes north of $10^{\circ} \mathrm{N}$ and those south of $20^{\circ} \mathrm{S}$ are made of long bands along latitudes, ranging from one side of the Ocean to the other, a pattern that is similar to that of the irradiance at the top of the atmosphere. This latitudinal distribution is mostly due to the influence of latitude on the irradiance pattern and to the permanence of the seasonal variability of cloud regimes at synoptic scales that flow from West to East in the northern latitudes and from East to West in the southern latitudes, as shown in the zoning of $K T$ discussed later. The tropical region does not exhibit such a latitudinal pattern. There may have several classes for a given range of latitudes. One may observe that the classes are homogeneous in space: they are not separated in several pieces.

Figure $2 b$ shows a map of the same 17 classes but where the colour of each class represents the yearly mean of the DSIS computed from each typical profile. The mean irradiance varies between $120 \mathrm{~W} \mathrm{~m}^{-2}$ in deep blue and $270 \mathrm{~W} \mathrm{~m}^{-2}$ 

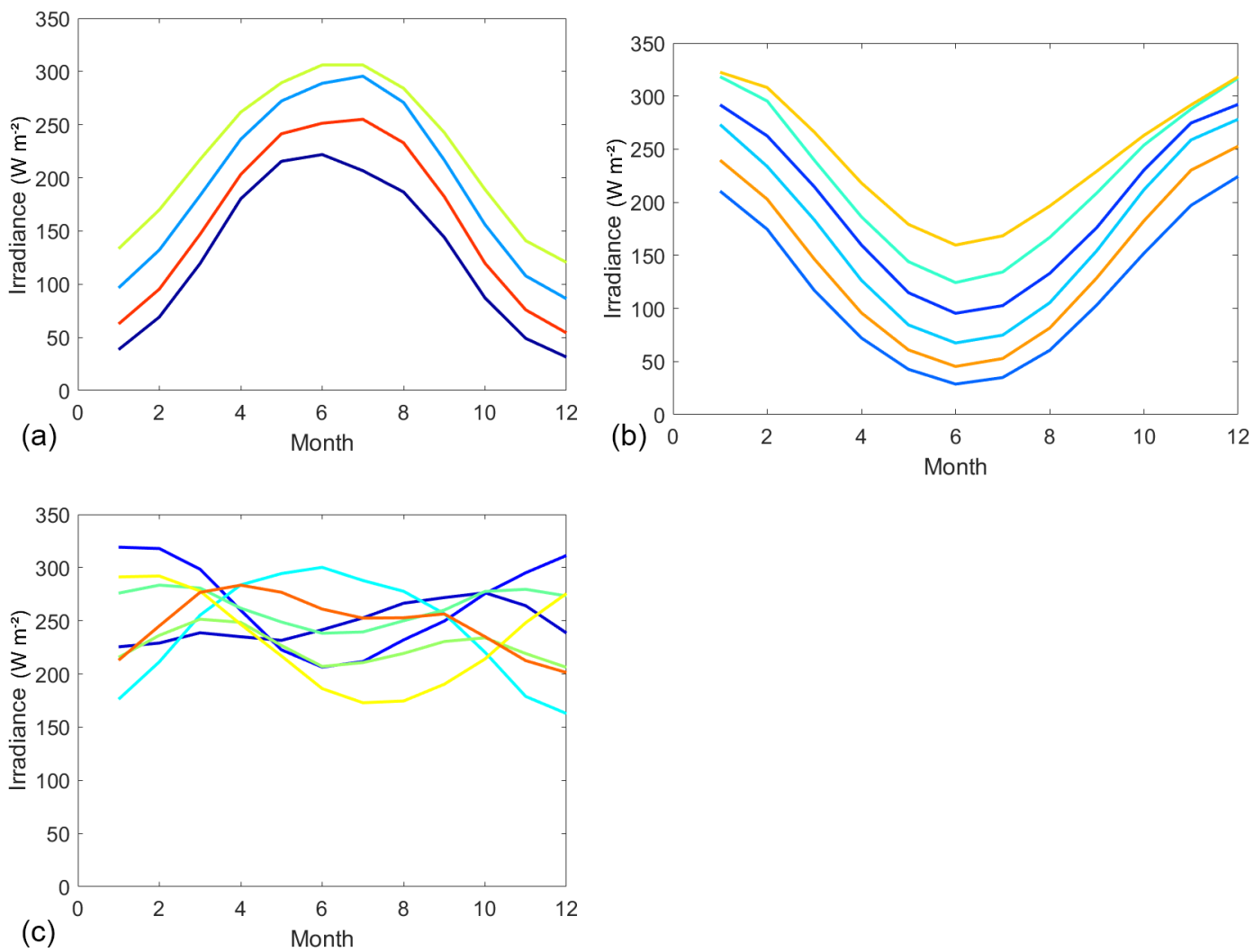

Figure 3. Typical profiles of DSIS for each class. Colours are the same as those in Fig. 3a. 4 northernmost classes (a), 6 southernmost classes (b), 7 tropical classes (c).

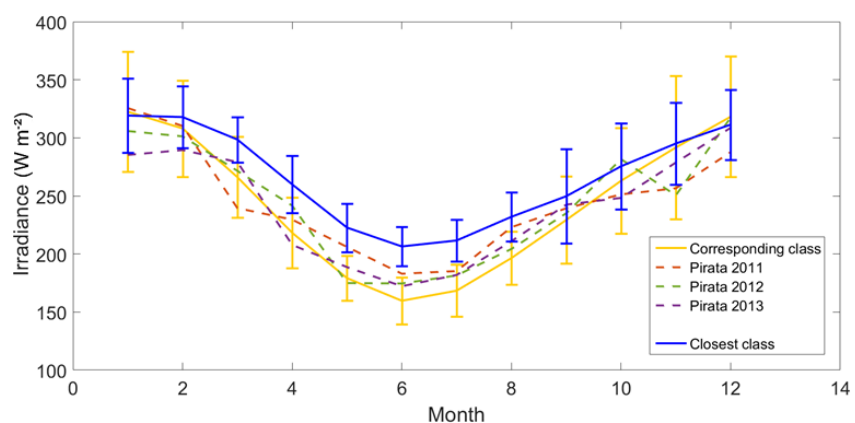

Figure 4. Yearly profiles of DSIS for the mooring at latitude $19^{\circ} \mathrm{S}$ and longitude $34^{\circ} \mathrm{W}$ for 2011 to 2013 . Yellow: typical profile of the corresponding class, the intervals denote the envelope of the variation within the class; Red: PIRATA measurement for 2011; Yellow: PIRATA measurement for 2012; Purple: PIRATA measurement for 2013; Blue: typical profile of the class which is the closest to the mooring.

in yellow. As expected, a latitudinal trend in the mean DSIS is observed with an increase from the poles towards the tropics. A maximum occurs between 0 and $20^{\circ} \mathrm{S}$, in central and western parts of the tropical basin. This may be related to the high pressure of the anticyclone semi-permanently located over the St Helena Island as discussed later.
The typical profile of each class is shown in Fig. 3a, b and c, with the same colour as its class in Fig. 2a. The profiles of the four northernmost classes are represented in Fig. 3a, those of the six southernmost classes in Fig. 3b, and the seven profiles for the tropical basin in Fig. 3c.

In the Northern Atlantic Ocean (Fig. 3a), the four profiles have fairly similar shapes. They exhibit a maximum of irradiance in June-July, corresponding to the boreal summer, and a minimum in December-January, i.e. the boreal winter. The maximum and minimum increase as the latitude decreases from the North to the tropics. As expected, opposite features are found in the Southern Atlantic Ocean (Fig. 3b). The six profiles offer fairly similar shapes and exhibit a maximum of irradiance in December-January, corresponding to the austral summer, and minimum in June-July, i.e. the austral winter. The maximum and the minimum increase as the latitude decreases from South to the tropics while their difference decreases. In the tropical region (Fig. 3c), the profiles are diverse and smooth without well marked peaks and troughs. 

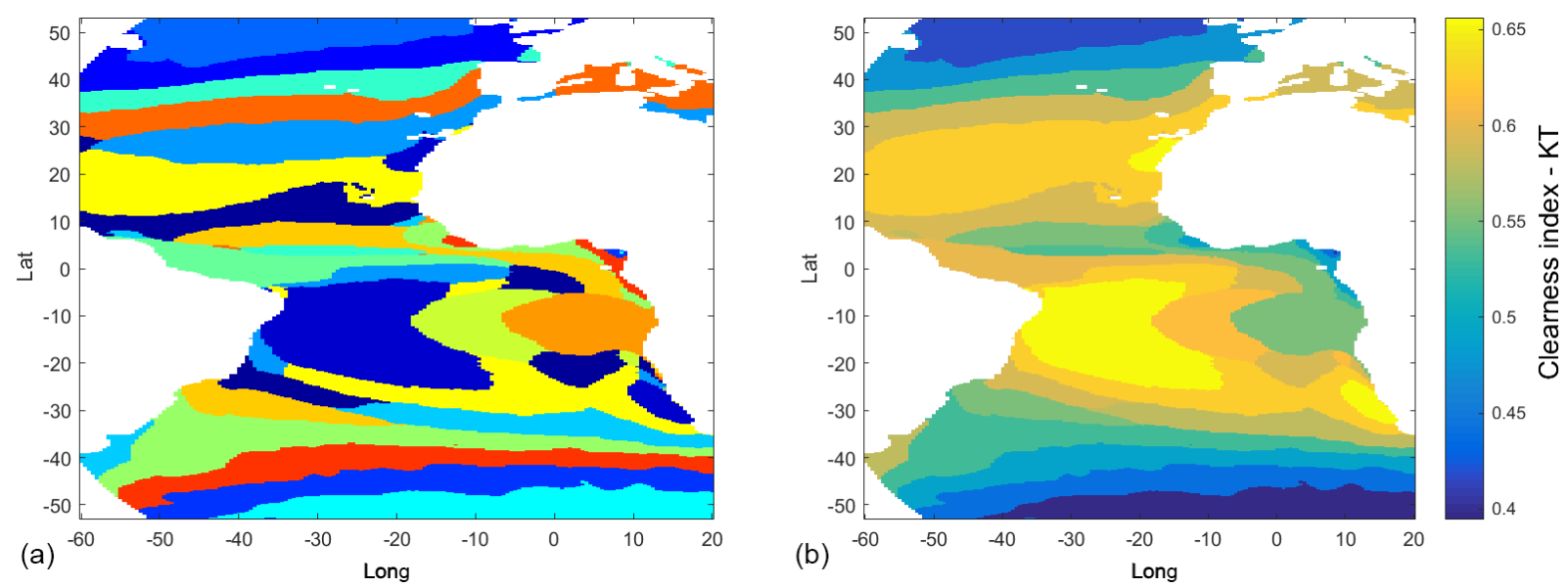

Figure 5. Map of the 17 classes of clearness index $K T$ (a). Map of the same classes but whose colour indicates the yearly mean of $K T$ (b).

\subsection{Validation of the zoning}

\subsubsection{Comparison between the yearly profiles from classes and PIRATA moorings}

In order to partly validate the resulting zoning, a comparison was performed between the yearly profiles measured at a moorings located at $\left(0^{\circ} \mathrm{N}, 10^{\circ} \mathrm{W}\right),\left(6^{\circ} \mathrm{S}, 10^{\circ} \mathrm{W}\right)$, and $\left(19^{\circ} \mathrm{S}\right.$, $34^{\circ} \mathrm{W}$ ) for two or three years and the typical profiles of the classes containing the geographical location of the buoys. If the zoning is correct, one expects the 2 or 3 individual PIRATA yearly profiles to be close to those of the corresponding class. As an example, Fig. 4 shows the three individual yearly profiles for the mooring located at $\left(19^{\circ} \mathrm{S}, 34^{\circ} \mathrm{W}\right)$ in dashed lines of different colours. The typical profile is shown in yellow. Also drawn are the ranges of variation for each month that are equal to three times the standard deviation of the class. This range corresponds to a $99.7 \%$ chance that any profile in this class lays in this envelope.

It can be seen that the three individual PIRATA profiles exhibit the same shape as the typical profile as expected. The PIRATA profiles fit well within the envelope, except for May and June 2011. Also shown in blue in this graph is the typical profile of the class which is the closest to the mooring but not containing it. As expected, the typical profile is quite different from the three individual PIRATA profiles, especially during the boreal summer. The three individual profiles are outside the envelope thus demonstrating a contrario that the class to which the PIRATA mooring belongs is the most similar to the individual PIRATA profiles. In this example, the typical profile is in agreement with the measurements at the mooring. Similar results were found for the two other moorings (not shown). Since the comparison was limited to three moorings, it cannot be concluded that the typical profiles are in agreement with the measurements at all moorings. Nevertheless, this partial validation brings confidence in the quality of the resulting zoning.

\subsubsection{Matches between classes and well-known physical and meteorological processes}

Figure 5a shows the map of the 17 classes of $K T$ with colours chosen randomly similarly to Fig. 3a. The shapes of the classes and their location differ from those for irradiance. Contrary to the previous zoning, the classes do not exhibit a marked latitudinal distribution, except the four classes north of $30^{\circ} \mathrm{N}$ and the three classes south of $40^{\circ} \mathrm{S}$. The latitudinal distribution for these northernmost and southernmost classes denotes the permanence of the seasonal variability of the cloud regime in these areas, with synoptic cloudy structures circulating from West to East in the northern latitudes and from East to West in the southern latitudes. Contrary to the irradiance zoning, several classes of $K T$ are made of several pieces.

Figure $5 \mathrm{~b}$ shows a map of the same 17 classes but where the colour represents the yearly mean of $K T$ computed from each yearly profile. The yellow colour corresponds to cloudfree conditions, with $K T$ close to 0.7 , and the blue colour corresponds to a strong extinction by the atmosphere, with $K T$ close to 0.4. As an example, the latter corresponds to a typical value at Paris in France (Greif et al., 2000; Page et al., 2001). A latitudinal trend of the mean $K T$ is observed with an increase from the poles towards the tropical region. The situation is different in the tropical basin; a maximum occurs between 0 and $25^{\circ} \mathrm{S}$, in western parts of the basin. This pattern will be discussed in the following paragraphs.

This zoning has many similarities to the mean annual clouds amount from the International Satellite Cloud Climatology Project (ISCCP) displayed in Fig. 6, despite differences in spatial resolution. Though the cloud optical depth is the most influential property of the clouds affecting the DSIS, the cloud amount may be considered as a proxy of $K T$ in a first approximation. The greater the cloud amount, the smaller $K T$. Figures $5 \mathrm{~b}$ and 6 show similar features: (i) a decreasing cloud amount (increasing $K T$ ) from northern 
ISCCP-D2 198307-200912 mean annual

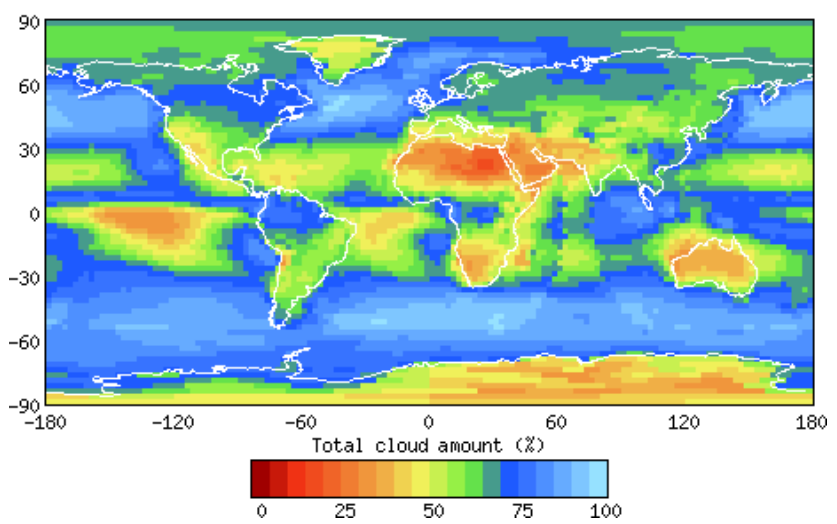

Figure 6. Map of the mean annual cloud amount for the period 1983-2009 from the International Satellite Cloud Climatology Project (ISCCP). Downloaded from https://isccp.giss.nasa.gov/ products/browsed2.html, last access: 2 January 2018.

or southern latitudes towards the tropical region, (ii) a local maximum in cloud amount (minimum in $K T$ ) around latitude $5^{\circ} \mathrm{N}$ which is related to the inter-tropical convergence zone, (iii) a low cloud amount (high $K T$ ) of crescent shape off the coasts of Brazil linked to the anticyclone of St Helena Island, and (iv) a high cloud amount (low KT) off the coasts of Angola and Namibia and in the Gulf of Guinea. The agreement between both maps is a further validation of the selected methodology.

Similarly to the DSIS, the typical profile of $K T$ of each class is shown in Fig. 7 with the same colour as its class in Fig. 5a.

The shapes of the typical profiles of $K T$ are fairly similar to the DSIS ones. $K T$ north of $40^{\circ} \mathrm{N}$ (blue curves) exhibits two local maxima in April and September, with a local minimum in-between in July. The profile becomes smoother as the latitude decreases towards the tropics: the maxima of April and September disappear and the July local minimum becomes an absolute maximum.

The profiles in the tropical region (Fig. 7c) are diverse and the amplitude of change from month to month can be large. Knowing that the cloud regime is the most influential variable on the seasonal variability, one may relate the strong decrease in $K T$ observed off the coasts of Angola from July to October (the two light blue curves) to an increase in the cloud coverage. This feature may be related to the Benguela current and its seasonal variations (Seinfeld et al., 2016). This observation is supported by the monthly maps of the cloud amount from the ISCCP (downloaded from https://isccp.giss.nasa. gov/products/browsed2.html, not shown). One may observe in Fig. 7c, a typical profile in deep blue of the class located in the western basin between 0 and $20^{\circ} \mathrm{S}$. This profile exhibits high and almost constant $K T$ around 0.65 , and may be related to the anticyclone semi-permanently located above the
St Helena Island. This meteorological phenomenon results in a low cloud amount all along the year, as seen on the cloud amount map from the ISCCP and mentioned above. These are examples of the matches between classes and meteorological processes, increasing the confidence in the clustering method.

\section{Ability of the configuration of the moorings to reflect the spatial variations of the monthly DSIS}

As several reasons to trust the zoning have been highlighted, one may use the zoning to analyse the geographical distribution of the 17 moorings with a view to capture the various yearly profiles in the tropical basin. As mentioned in Sect. 1, if there is one or more PIRATA mooring in each class, it can be concluded than the configuration of the PIRATA network is appropriate to reflect the spatial variations of the monthly DSIS. Figure 8 shows the location of the 17 buoys superimposed on the map of the DSIS classes.

One observes that there are one or more moorings in each of the classes between 0 and $30^{\circ} \mathrm{N}$. It may be concluded that the network may capture the spatial variations of the monthly DSIS in this area. The southern area of the tropical basin is not represented in the same proportion. The three classes between 20 and $30^{\circ} \mathrm{S}$ are not represented by any mooring and thus the network does not capture the spatial variations of the monthly DSIS in this area. This may induce misinterpretation of the data at synoptic scales. For instance, these three classes exhibit the lowest yearly means of DSIS in the tropical basin: between 200 and $240 \mathrm{~W} \mathrm{~m}^{-2}$. As a consequence, if only the in-situ measurements are taken into account in a calculation of the DSIS received by the whole tropical basin, an overestimation of the irradiance will occur. In addition, this map illustrates that the computation of latitudinal or longitudinal averages of irradiance based on the sole use of measurements from moorings should take into account the spatial representativeness of these moorings, and in any case cannot be undertaken if a zone is misrepresented by the network of moorings.

\section{Discussion}

The selected methodology may apply to other oceanic basins provided archives of gridded DSIS data are available. The selected methodology may apply to other variables than the DSIS, such as sea surface temperature which is routinely monitored by satellites. There are a number of arbitrary choices, e.g. clustering technique or input state vectors that merit a deeper discussion beyond the scope of this work which is a preliminary step in a climatic description of the changes in space and time of the irradiance in the tropical Atlantic Ocean.

Zoning may help in designing or evolving a network. The recent advances in the assessment of DSIS from satellite data 

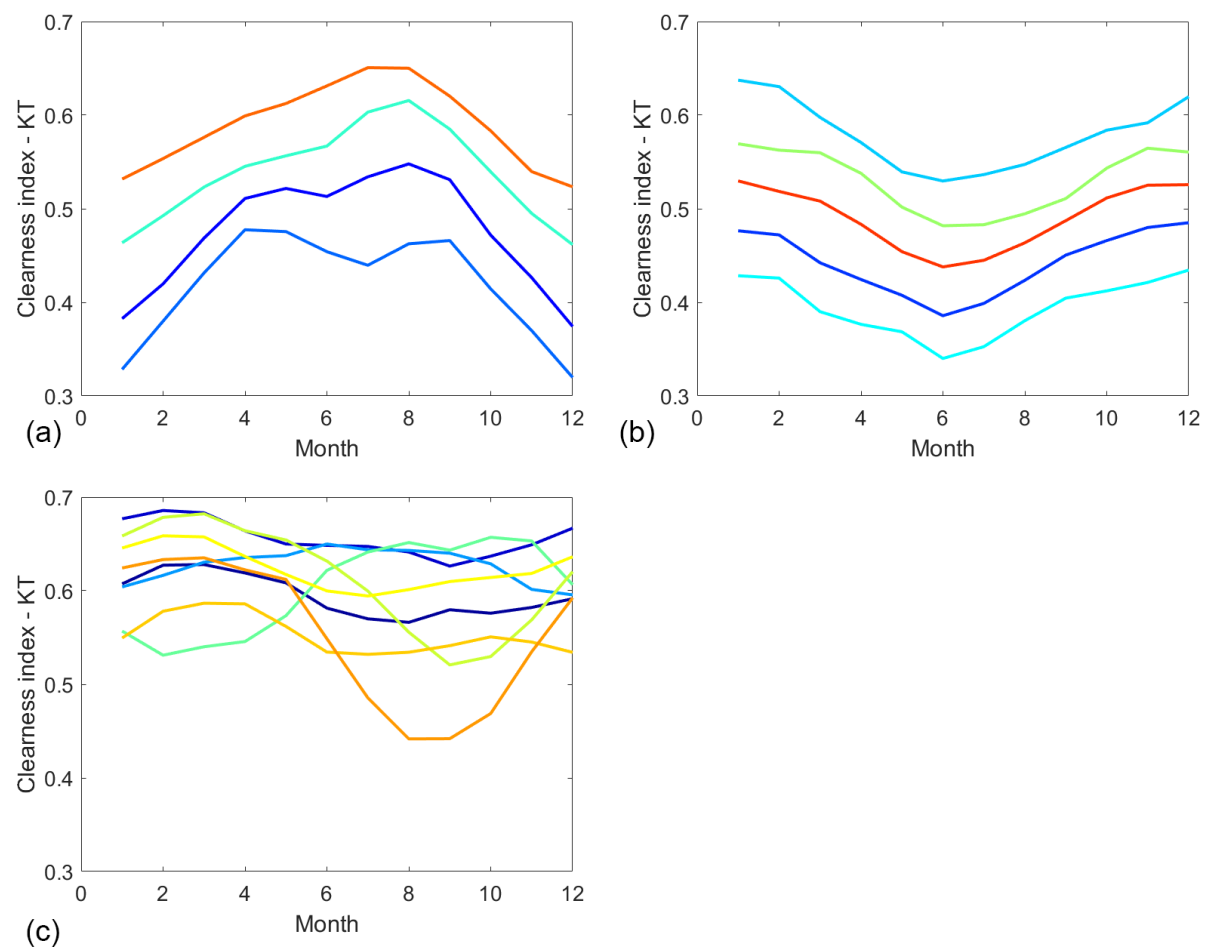

Figure 7. Typical profiles of $K T$ for each class. Colours are the same as those in Fig. 6a. 4 northernmost classes (a), 5 southernmost classes (b), 8 tropical classes (c).

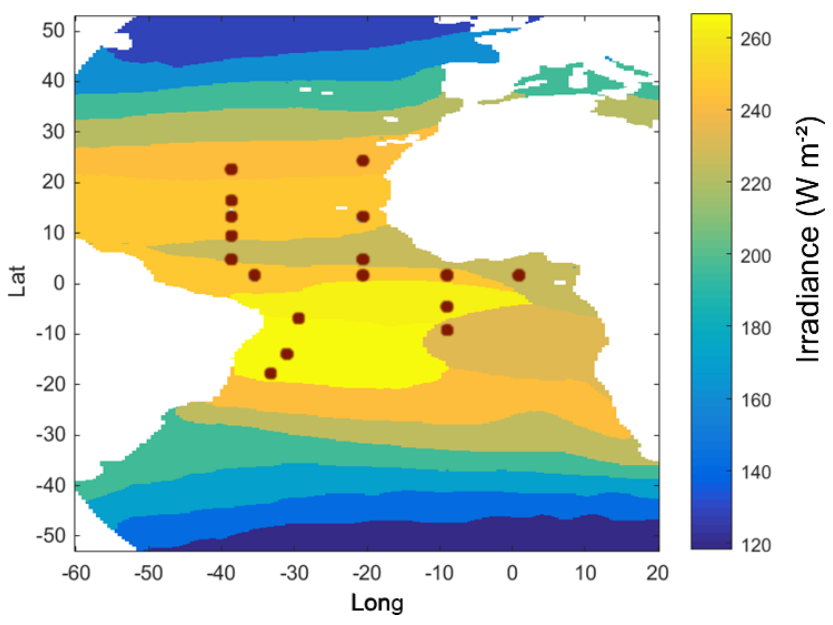

Figure 8. Location of the 17 buoys superimposed on the map of classes of DSIS. The colour indicates the mean yearly DSIS.

may help in revising and completing the first studies, done several years ago, in the context of the deployment of the PIRATA network. Considering the important financial, scientific and material effort that occurs in the deployment of a buoy, the satellite estimates could aid decision-making on the number of moorings to deploy and the selection of appropriate geographical locations.
The present analysis only looked at DSIS. PIRATA moorings are equipped with other instruments than pyranometers, which measure more than 20 atmospheric and subsurface variables. All of these variables have to be taken into account for designing network. The zoning approach can be used on a bundle of variables, knowing that other observables may be subject to other considerations compare to DSIS. However, the analyses of the results would be much more complex with respect to decision making.

\section{Conclusions}

A map of similar zones with respect to the yearly profile of monthly means and standard deviations of the DSIS has been realized over the Atlantic Ocean thanks to a clustering technique. It was found that the resulting zones reproduce the measured DSIS at the three moorings in the tropical Atlantic Ocean having enough measurements to perform the comparison. Zones have clear connections with the climatology of the region and circulation regimes. The geographical repartition of the moorings has been analysed with regard to the zoning. The zones are well covered by the PIRATA network except a few. It was also found that the computation of latitudinal or longitudinal averages of irradiance may be wrong if based solely on measurements from moorings without taking into account the spatial representativeness of a mooring. Fi- 
nally, this zoning highlights the high quality of the PIRATA network regarding the synoptic scales of the DSIS.

Data availability. PIRATA measurements performed every 2 min were downloaded from the web site (www.pmel.noaa.gov/tao/ drupal/disdel/, last access: 9 July 2018) of the National Oceanic and Atmospheric Administration (NOAA) of the USA. The authors acknowledge the help of the GTMBA Project Office of NOAA/PMEL in getting the data and the PIRATA team for servicing the network and freely providing the data. Time series of HelioClim-3v5 data were downloaded from the SoDa Service web site (http://www. soda-pro.com/, last access: 9 July 2018) managed by the company Transvalor. Data are available to anyone for free for years 20042006 as a GEOSS Data-CORE (GEOSS Data Collection of Open Resources for Everyone) and for a charge for the most recent years with the amount depending on requests and requester. The time series used in this article corresponds to these data remapped. The dataset is available for free in CSV format by request to Mélodie Trolliet. A similar dataset with a DOI will be available soon, in the context of another study (article to be submitted in the forthcoming weeks).

Author contributions. All authors contributed equally to this work.

Competing interests. The authors declare that they have no conflict of interest.

Special issue statement. This article is part of the special issue "17th EMS Annual Meeting: European Conference for Applied Meteorology and Climatology 2017'. It is a result of the EMS Annual Meeting: European Conference for Applied Meteorology and Climatology 2017, Dublin, Ireland, 4-8 September 2017.

Acknowledgements. The authors thank the anonymous reviewers and the Editor for the valuable and encouraging comments greatly help in improving the readability of this article. They acknowledge the key role of the PIRATA team in servicing the network and freely providing the data. The authors state that the PIRATA network is a unique and valuable means of studying and monitoring the surface irradiance in the tropical Atlantic Ocean and hope it will receive support for operations to further enrich the datasets. The authors acknowledge the help of the GTMBA Project Office of NOAA/PMEL in acquiring the data. Time-series of HelioClim-3v5 data were downloaded from the SoDa Service web site (http://www.soda-pro.com/, last access: 9 July 2018) managed by Transvalor. The authors thank the ISCCP team for their web site (https://isccp.giss.nasa.gov/, last access: 9 July 2018).

Edited by: Rasmus Benestad

Reviewed by: two anonymous referees

\section{References}

Augustine, J. A., DeLuisi, J. J., and Long, C. N.: SURFRAD - A national surface radiation budget network for atmospheric research, B. Am. Meteorol. Soc., $\quad 81, \quad 2341-2358, \quad$ https://doi.org/10.1175/15200477(2000)081<2341:SANSRB>2.3.CO;2, 2000.

Bengulescu, M., Blanc, P., and Wald, L.: Characterizing temporal variability in measurements of surface solar radiation and its dependence on climate, Energy Proced., 97, 164-171, https://doi.org/10.1016/j.egypro.2016.10.045, 2016.

Bengulescu, M., Blanc, P., Boilley, A., and Wald, L.: Do modelled or satellite-based estimates of surface solar irradiance accurately describe its temporal variability?, Adv. Sci. Res., 14, 35-48, https://doi.org/10.5194/asr-14-35-2017, 2017.

Bengulescu, M., Blanc, P., and Wald, L.: On the intrinsic timescales of temporal variability in measurements of the surface solar radiation, Nonlin. Processes Geophys., 25, 19-37, https://doi.org/10.5194/npg-25-19-2018, 2018.

Bogárdi, I., Bárdossy, A., and Duckstein, L.: Multicriterion network design using geostatistics, Water Resour. Res., 21, 199 208, https://doi.org/10.1029/WR021i002p00199, 1985.

Boilley, A. and Wald, L.: Comparison between meteorological reanalyses from ERA-Interim and MERRA and measurements of daily solar irradiation at surface, Renew. Energ., 75, 135-143, https://doi.org/10.1016/j.renene.2014.09.042, 2015.

Bourlès, B., Lumpkin, R., McPhaden, M. J., Hernandez, F., Nobre, P., Campos, E., Yu, L., Planton, S., Busalacchi, A., Moura, A. D., Servain, J., and Trotte, J.: The PIRATA Program: History, accomplishments, and future directions, B. Am. Meteorol. Soc., 89, 1111-1125, https://doi.org/10.1175/2008BAMS2462.1, 2008.

Bras, R. L. and Rodríguez-Iturbe, I.: Network design for the estimation of areal mean of rainfall events, Water Resour. Res., 12, 1185-1195, https://doi.org/10.1029/WR012i006p01185, 1976.

Diabaté, L., Blanc, P., and Wald, L.: Solar radiation climate in Africa, Sol Energ., 76, 733-744, https://doi.org/10.1016/j.solener.2004.01.002, 2004.

Eissa, Y., Korany, M., Aoun, Y., Boraiy, M., Abdel Wahab, M., Alfaro, S., Blanc, P., El-Metwally, M., Ghedira, H., and Wald, L.: Validation of the surface downwelling solar irradiance estimates of the HelioClim-3 database in Egypt, Remote Sens-Basel, 7, 9269-9291, https://doi.org/10.3390/rs70709269, 2015.

Foltz, G. R., Evan, A. T., Freitag, H. P., Brown, S., and McPhaden, M. J.: Dust accumulation biases in PIRATA shortwave radiation records, J. Atmos. Ocean. Technol., 30, 1414-1432, https://doi.org/10.1175/JTECH-D-12-00169.1, 2013.

Greif, J. J., Scharmer, K., Aguiar, R., Albuisson, M., Beyer, H.-G., Borisenkov, E. P., Bourges, B., Czeplak, G., Lund, H., Joukoff, A., Page, J. K., Terzenbach, U., and Wald, L.: The European Solar Radiation Atlas : Database, Models and Exploitation Software, Vol. 2, Presse des Mines, Paris, France, 290 pp., 2000.

Gschwind, B., Ménard, L., Albuisson, M., and Wald, L.: Converting a successful research project into a sustainable service: the case of the SoDa Web service, Environ. Modell. Softw., 21, 15551561, https://doi.org/10.1016/j.envsoft.2006.05.002, 2006.

Korany, M., Boraiy, M., Eissa, Y., Aoun, Y., Abdel Wahab, M. M., Alfaro, S. C., Blanc, P., El-Metwally, M., Ghedira, H., Hungershoefer, K., and Wald, L.: A database of multi-year (2004-2010) quality-assured surface solar hourly irradiation measurements 
for the Egyptian territory, Earth Syst. Sci. Data, 8, 105-113, https://doi.org/10.5194/essd-8-105-2016, 2016.

Lefèvre, M., Diabaté, L., and Wald, L.: Using reduced datasets ISCCP-B2 from the Meteosat satellites to assess surface solar irradiance, Sol. Energ., 81, 240-253, https://doi.org/10.1016/j.solener.2006.03.008, 2007.

Marchand, M., Al-Azri, N., Ombe-Ndeffotsing, A., Wey, E., and Wald, L.: Evaluating meso-scale change in performance of several databases of hourly surface irradiation in South-eastern Arabic Pensinsula, Adv. Sci. Res., 14, 7-15, https://doi.org/10.5194/asr-14-7-2017, 2017.

Marchand, M., Ghennioui, A., Wey, E., and Wald, L.: Comparison of several satellite-derived databases of surface solar radiation against ground measurement in Morocco, Adv. Sci. Res., 15, 2129, https://doi.org/10.5194/asr-15-21-2018, 2018.

Muneer, T. and Fairooz, F.: Quality control of solar radiation and sunshine measurements - lessons learnt from processing worldwide databases, Build. Serv. Eng. Res. T., 23, 151-166, https://doi.org/10.1191/0143624402bt038oa, 2002.

Page, J., Albuisson, M., and Wald, L.: The European solar radiation atlas: a valuable digital tool, Sol. Energ., 71, 81-83, https://doi.org/10.1016/S0038-092X(00)00157-2, 2001.

Qu, Z., Gschwind, B., Lefevre, M., and Wald, L.: Improving HelioClim-3 estimates of surface solar irradiance using the McClear clear-sky model and recent advances in atmosphere composition, Atmos. Meas. Tech., 7, 3927-3933, https://doi.org/10.5194/amt-7-3927-2014, 2014.

Rigollier, C., Lefèvre, M., and Wald, L.: The method Heliosat-2 for deriving shortwave solar radiation from satellite images, Sol. Energ., 77, 159-169, doi 10.1016/j.solener.2004.04.017, 2004.

Seinfeld, J. H., Bretherton, C., Carslaw, K. S., Coe, H., DeMott, P. J., Dunlea, E. J., Feingold, G., Ghan, S., Guenther, A. B., Kahn, R., Kraucunas, I., Kreidenweis, S. M., Molina, M. J., Nenes, A., Penner, J. E., Prather, K. A., Ramanathan, V., Ramaswamy, V., Rasch, P. J., Ravishankara, A. R., Rosenfeld, D., Stephens, G., and Wood, R.: Aerosol-cloud interactions in climate, P. Natl. Acad. Sci. USA, 113, 5781-5790, https://doi.org/10.1073/pnas.1514043113, 2016.

Servain, J., Busalacchi, A. J., McPhaden, M. J., Moura, A. D., Reverdin, G., Vianna, M., and Zebiak, S. E.: A pilot research moored array in the Tropical Atlantic (PIRATA), B. Am. Meteor. Soc., 79, 2019-2032, https://doi.org/10.1175/15200477(1998)079<2019:APRMAI>2.0.CO;2, 1998.
Stauffer, D. R., Seaman, N. L., Hunter, G. K., Leidner, S. M., Lario-Gibbs, A., and Tanrikulu, S.: A field-coherence technique for meteorological field-program design for air quality studies. Part I: Description and interpretation, J. Appl. Meteor., 39, 297-316, https://doi.org/10.1175/15200450(2000)039<0297:AFCTFM>2.0.CO;2, 2000.

Stokes, G. M. and Schwartz, S. E.: The Atmospheric Radiation Measurement (ARM) Program: Programmatic background and design of the cloud and radiation test bed, B. Am. Meteorol. Soc., 75, 1201-1222, https://doi.org/10.1175/15200477(1994)075<1201:TARMPP>2.0.CO;2, 1994.

Thomas, C., Wey, E., Blanc, P., and Wald, L.: Validation of three satellite-derived databases of surface solar radiation using measurements performed at 42 stations in Brazil, Adv. Sci. Res., 13, 81-86, https://doi.org/10.5194/asr-13-81-2016, 2016a.

Thomas, C., Wey, E., Blanc, P., Wald, L., and Lefèvre, M.: Validation of HelioClim-3 version 4, HelioClim-3 version 5 and MACC-RAD using 14 BSRN stations, Energy Proced., 91, 1059-1069, https://doi.org/10.1016/j.egypro.2016.06.275, 2016b.

Trolliet, M., Walawender, J. P., Bourlès, B., Boilley, A., Trentmann, J., Blanc, P., Lefèvre, M., and Wald, L.: Estimating downwelling solar irradiance at the surface of the tropical Atlantic Ocean: A comparison of PIRATA measurements against several re-analyses and satellite-derived data sets, Ocean Sci. Discuss., https://doi.org/10.5194/os-2017-95, in review, 2017.

Vinnikov, K. Y., Robock, A,. Qiu, S., and Entin, J. K.: Optimal design of surface networks for observation of soil moisture, J. Geophys. Res., 104, 19743-19749, https://doi.org/10.1029/1999JD900060, 1999.

Ward, J. W.: Hierarchical grouping to optimize an objective function, Journal American Statistics Association, 58, 236-244, 1963.

Wolfe, D. E. and Gutman, S. I.: Developing an operational, surface-based, GPS, water vapor observing system for NOAA: Network design and results, J. Atmos. Ocean. Technol., 17, 426-440, https://doi.org/10.1175/15200426(2000)017<0426:DAOSBG>2.0.CO;2, 2000. 